\title{
Erratum to: Design of Low Cost Blood Glucose Sensing System Using Diffused Reflectance Near-Infrared Light
}

Jyoti Yadav, Asha Rani, Vijander Singh and Bhaskar Mohan Murari

\section{Erratum to:}

Chapter "Design of Low Cost Blood Glucose Sensing System Using Diffused Reflectance Near-Infrared Light" in: G.M. Perez et al. (eds.), Networking Communication and Data Knowledge Engineering, Lecture Notes on Data Engineering and Communications Technologies 3, https://doi.org/10.1007/978-981-10-4585-1_17

In the original version of the book, Reference 17 "G. Guevara, Joint optical-electrical technique for non-invasive glucose monitoring, Mex. J. Phys. 56(5): 430-434, 2010. doi:http://www.scielo.org.mx/pdfrmf/v56n5/v56n5a12" has been now changed as "E. Guevara, F.J. González, Joint optical-electrical technique for non-invasive glucose monitoring, Mex. J. Phys. 56(5): 430-434, 2010. doi:http://www.scielo.org.mx/ scielo.php?script=sci_arttext\&pid=S0035-001X201000050001" in chapter "Design of Low Cost Blood Glucose Sensing System Using Diffused Reflectance Near-Infrared Light", which is a belated correction.

The updated online version of this chapter can be found at https://doi.org/10.1007/978-981-10-4585-1_17 